\title{
Mudanças no Comportamento do Consumidor nos Cenários pós COVID-19: O Consumidor Brasileiro em 2025
}

\author{
Andrea Carolina Droguett Jamett ${ }^{1 *}$, Luciano Teixeira Schweizer ${ }^{2}$
}

http://orcid.org/0000-0002-2827-4818 / Universidade de Brasilia (UnB), Brasil

2 http://orcid.org/0000-0002-0044-1928 / Banco Interamericano de Desenvolvimento (BID), Brasil

\section{Resumo}

Mudanças no comportamento do consumidor são discutidas nas mídias com ênfase nas projeções da população em relação aos comportamentos de preservação coletiva na Pandemia da doença do novo coronavírus (COVID-19). Questiona-se como o consumidor agirá e quais as consequências para as organizações no pós-contágio. O artigo visa responder a essa pergunta com o uso de cenários prospectivos e do Modelo da Perspectiva Comportamental para propor alternativas de estratégias de mercado e de comunicação para as organizações.

Palavras-chave: comportamento do consumidor, COVID-19, Modelo da Perspectiva Comportamental.

\section{Changes in Consumer Behavior in post-COVID-19 Scenarios: The Brazilian Consumer in 2025}

Abstract

Changes in consumer behavior have been discussed in the media with an emphasis on community projections of collective preservation behaviors in the Corona Virus Disease 19 (COVID-19) pandemic. It is questioned how the consumer will act and what will be the consequences for post-contagion organizations. The article proposes to respond using prospective scenarios and the Behavioral Perspective Model to indicate alternatives for marketing and communication strategies for organizations.

Keywords: consumer behavior, COVID-19, Behavior Perspective Model.

\section{Cambios en el Comportamiento del Consumidor en los Escenarios post COVID-19: \\ El Consumidor Brasileño en 2025}

Resumen

Cambios en el comportamiento del consumidor han sido discutidos en los medios de comunicación con énfasis en las proyecciones comunitarias de los comportamientos de preservación colectiva en la pandemia del COVID19. Se cuestiona cómo actuará el consumidor y cuáles serán las consecuencias para las organizaciones post-contagio. El artículo propone responder a esa pregunta con el uso de escenarios prospectivos y el Modelo de Perspectiva Conductual para proponer estrategias alternativas de mercado y comunicación para las organizaciones.

Palabras clave: comportamiento del consumidor, COVID-19, Modelo de Perspectiva Conductual 


\section{Uma Crise Recorrente, mas Algo Novo}

Em momentos como o vivido com a Pandemia e a crise econômica provocada pela COVID-19, a história da sociedade depara-se com uma pluralidade de caminhos alternativos para seu desenvolvimento. Esses caminhos são desconhecidos e têm poucas conexões factuais com o passado recente vivido, resultando em desafio para projetar possíveis cenários futuros em que os indivíduos tomarão as suas decisões. Resultam em dificuldades para analisar como o comportamento será afetado pelos estímulos nesse novo ambiente e pelas consequências do comportamento em geral e, especialmente, no comportamento do consumidor brasileiro.

Este tipo de momento na sociedade foi descrito por Lewis e Bridger (2000, p. 1), tomando emprestado a imagem do "Tesarac" do poeta e autor norte-americano Shel Siverstein. O termo é utilizado para descrever aqueles períodos da história em que ocorrem mudanças sociais e culturais importantes, durante os quais a sociedade se torna cada vez mais caótica e confusa antes de reorganizar-se de maneira que ninguém poderia prever com precisão ou facilidade. As mudanças que acontecem nesses momentos são de tal magnitude e profundidade que ninguém que tenha nascido após essa "dobradura do tempo" será capaz de entender completamente como era a vida antes de sua ocorrência.

Se estamos ou não no meio de uma transição da magnitude de um "Tesarac" é algo desconhecido. Contudo, para lidar com este tipo de ambiente operacional, as ferramentas de projeção perdem sua eficácia. Em seu lugar, as soluções de prospectiva se apresentam como sendo as mais eficazes, não somente por permitir delinear cenários operacionais alternativos, como por poder dar conta de horizontes temporais mais amplos.

Interagindo com esse ambiente, encontram-se os consumidores em um processo permanente de "produção" de comportamento. O comportamento do consumidor passa a configurar como uma variável passível de ser igualmente projetada no futuro, de forma a obter informação de como e em que direção mudará. Ou, sob outra perspectiva, de que forma é possível intervir na promoção de comportamentos "bons" ou comportamentos caracterizados como eventos filogeneticamente importantes (Phylogenetically Important Event - PIE; Baum, 2015) para a preservação da coletividade. No momento presente, já é possível observar algumas mudanças e tendências dessas mudanças no que se refere às decisões de compra de alguns produtos e serviços. Há aumento da procura e consumo de alguns (p. ex.: produtos de limpeza, alimentos não perecíveis) e diminuição de outros (p. ex.: roupas, cosméticos) (Oliveira, 2020).

O comportamento atual do consumidor coloca em evidência, por um lado, as consequências de escolhas passadas, isto é, o seu histórico de consumo. Por outro lado, evidenciam-se o efeito do cenário atual com maiores restrições (p. ex.: as leis permitindo somente operações de negócios essenciais), o menor acesso a recursos (p. ex.: consumidores que perderam emprego) e os estímulos sinalizadores de consequências incertas. Por exemplo, os estímulos comunicacionais que sinalizam efeitos ambíguos ou contrapostos quanto às escolhas, que podem estar orientadas a benefícios coletivos ou a benefícios puramente individuais (p. ex.: há presença de estímulos para estocagem de certos produtos, versus as chamadas a abastecer-se somente do necessário em respeito a outros consumidores).

A partir da observação do comportamento utilizando o Modelo da Perspectiva Comportamental (Behavior Perspective Model - BPM, pela sua sigla em inglês), proposto por Foxall (2016), em que o comportamento do consumidor é analisado como a interação entre eventos antecedentes, ações do consumidor e eventos consequentes; muitos questionamentos surgem. Questiona-se aspectos relacionados às mudanças que virão a consolidar-se como parte do comportamento futuro dos indivíduos, materializados em possíveis cenários de consumo. O que irá gerar, consequentemente, mudanças nas estratégias e ações de marketing e comunicacionais das organizações privadas e públicas, na tentativa de adaptar-se e fortalecer seus objetivos e posicionamento.

Existirão mudanças advindas de manifestações sociais? Emergirão novos modos de vida orientados a comportamentos bons, como aponta Baum (2015), e filogeneticamente importantes? Quanto tempo durarão as contingências? Elas pressionarão por efeitos no comportamento? Os efeitos nos comportamentos são sustentáveis no tempo? São perguntas que emergem em meio ao que futuramente poder-se-á caracterizar como um "tesarac".

\section{Podemos Aprender Algo com o Passado?}

As duas últimas pandemias de proporções talvez igualáveis à atual foram a da gripe espanhola de 1918-20 e a da Síndrome da Imunodeficiência Adquirida (Acquired Immunodeficiency Syndrome

AIDS). Ambas trouxeram mudanças de comportamento importantes, como o hábito de lavar as mãos com mais frequência, no caso da gripe espanhola; e o comportamento do "sexo seguro" com a AIDS. No estudo feito por Balinska e Rizzo (2009), foi revisada a literatura científica relevante para as epidemias de gripes do século $\mathrm{XX}^{2}$ e da Síndrome Respiratória Aguda Grave (Severe Acute Respiratory Syndrome - SARS), buscando alterações no comportamento da população em resposta às consequências sociais de uma pandemia.

Para a gripe espanhola (1918-20), o estudo encontrou que algumas respostas comportamentais às medidas de intervenção não-farmacêutica (MInF) terminaram por comprometer sua efetividade. Houve dificuldade em manter a rigorosidade no cumprimento das medidas, uma vez passada a onda preliminar de medo; seja por razões ambientais (manter as pessoas dentro de casa nas noites quentes), por razões de estresse psicológico devido ao isolamento ou, simplesmente, porque deixaram de ser obrigatórias.

As sensações de caos e perturbação social foram alimentadas por fatores como recomendações conflitantes entre autoridades nacionais e locais. Além disso, muitas informações imprecisas eram divulgadas como consequência da censura da mídia (sob as mais variadas justificativas: lógica de guerra, impacto na imagem local ou internacional da cidade ou país ou, ainda, sob a justificativa de evitar pânico). Por fim, havia também o alto índice de absenteísmo de profissionais da medicina, seja por demandas da guerra ou pelo pânico que se alastrou pela sociedade levando os médicos a abandonarem os doentes.

Há evidências, segundo Balinska e Rizzo (2009), de que os grupos sociais e regiões pobres sofreram uma maior mortalidade, que também estava associada à desnutrição, à falta de roupa adequada e a condições precárias de habitação. A pandemia de 1918-1920 também gerou, pela sua própria dinâmica social, consequências de novas enfermidades como a "gripe crônica nervosa" e a depressão resultante da longa convalescença.

Balinska e Rizzo (2009) apontam para o fato de que a confiança do público é influenciada pelo histórico de experiências com emergências de saúde e pela maneira como, no momento presente, as autoridades lidam com emergências. No caso de uma pandemia de gripe grave, manter a esperança é importante, mas

1 A palavra é tomada como um neologismo criado por Shel Silverstein, porém especula-se que foi uma adaptação linguística da palavra tesseract, em português tesserato ou hipercubo, figura geométrica de quatro dimensões (altura, profundidade, largura e tempo).

2 Epidemias de 1918-1920, 1957-1958, 1969-1969. 


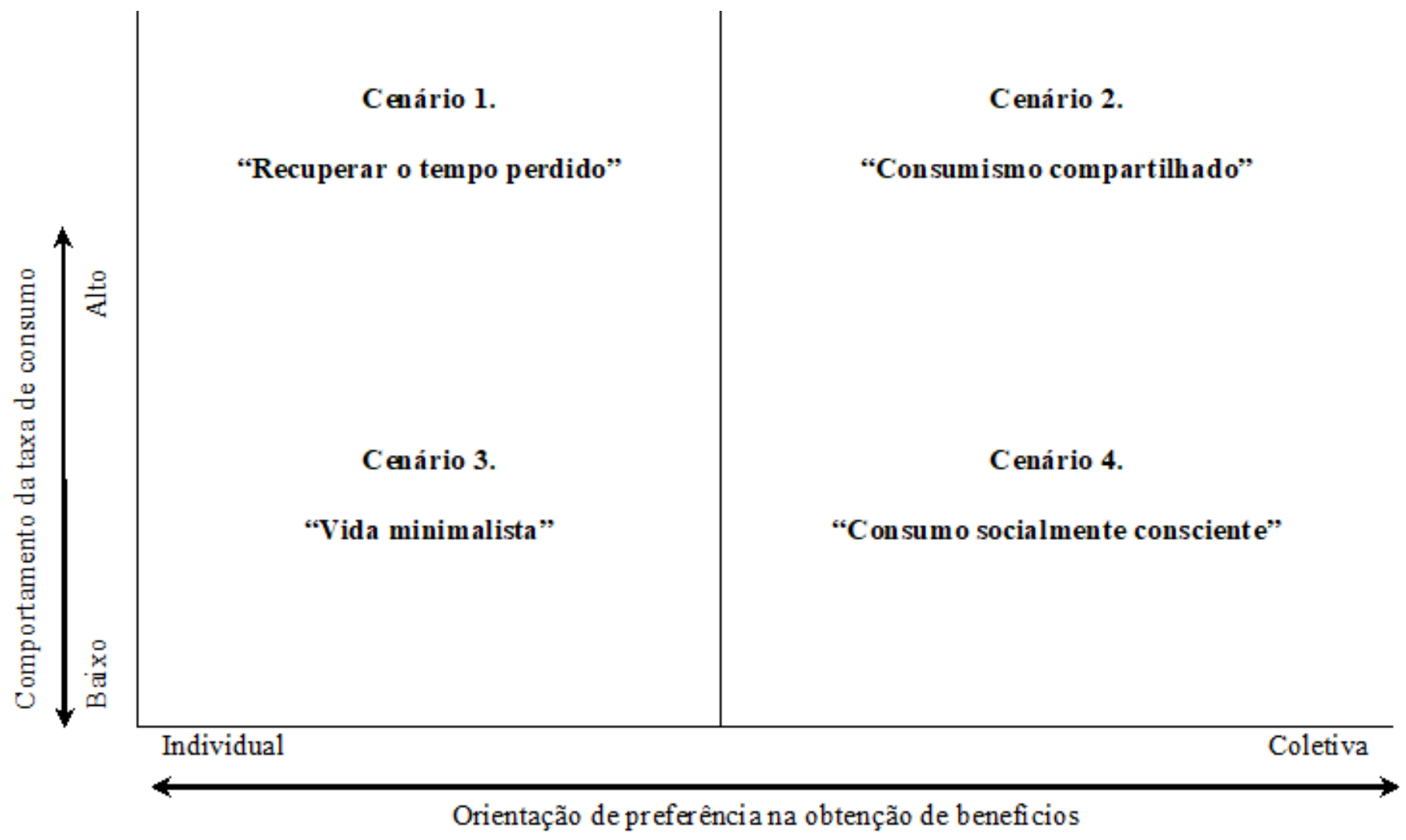

Figura 1. Modelo da Perspectiva Comportamental (BPM). Adaptado de Foxall, Oliveira-Castro, James, Yani-de-Soriano e Sigurdsson (2006)

é imprescindível estar preparado para o pior. Essa tem sido a estratégia comunicacional mais efetiva, uma vez que são grandes as dificuldades em prever a dinâmica de transmissão da gripe, a disponibilidade de profissionais de saúde e o nível de "especulação empresarial" (p. ex.: vendas de produtos farmacêuticos, equipamentos de proteção e vacinas falsificados, soluções "milagrosas" e remédios "naturais"), fatores recorrentes nas experiências e de provável repetição em casos futuros.

Uma diferença importante entre a atual pandemia e as situações passadas descritas é o acesso à informação por meio da mídia e da internet. Esses meios são mais eficazes para identificar e disseminar as medidas que estão sendo tomadas em outros países, o que pode levar ao aumento na demanda do público por políticas públicas de saúde, ao ajuste nas percepções conflitantes de adequação das intervenções e na alocação de recursos públicos para enfrentar a epidemia.

No caso da epidemia da AIDS, a reação do público foi mais difusa, excetuando-se a primeira onda da pandemia ocorrida na década de 1980, que gerou modificações comportamentais imediatas como a redução do número de parceiros, o sexo seguro com o uso de preservativos e o não compartilhamento de seringas entre usuários de drogas (Barata, 2006). A AIDS também trouxe a necessidade de lidar com novos problemas, como o convívio prolongado com a epidemia, seus ciclos difusos e ondas repentinas. Isso requer sistemas de monitoramento permanente e medidas para manter a "onda permanentemente achatada", bem como para lidar com os estigmas sociais que pudessem tornar as ondas e brotes ainda mais imprevisíveis e invisíveis e, assim, mais arriscados para a sociedade (Becker \& Joseph, 1988).

\section{Uma Alternativa de Modelo Comportamental para Análise}

As organizações, privadas e públicas, têm sua efetividade e desempenho econômico fortemente vinculadas às preferências dos consumidores. A antecipação de sua mudança e movimentos são fontes estratégicas de competitividade e eficácia organizacional. A utilização de modelos que permitam explicar o comportamento do consumidor em diferentes contextos e cenários atuais e futuros contribui para antecipar ações de comunicação e de marketing. Isso permite, no caso das empresas privadas, o desenvolvimento de atividades de marketing de forma a segmentar mercados, posicionar marcas e produtos e conquistar clientes (Fagerstrom, Stratton, \& Foxall, 2015).

No caso das organizações públicas, a explicação e previsão do comportamento do consumidor permite implementar ações comunicacionais e de marketing, assim como políticas públicas. Essas ações visam a ajustar as políticas, regulamentos e instrumentos de estímulos ou de restrições de comportamentos específicos. Além disso, podem ter função de apoio ao desenvolvimento de novas empresas, promoção de medidas para a sustentabilidade de pequenas empresas, políticas vinculadas ao emprego, restrição ao consumo de certos bens e serviços e aumento ou diminuição de impostos para certos segmentos empresariais.

A preferência do consumidor, observada pelo comportamento de escolha, tem sido explicada pela abordagem analítico-comportamental por meio da unidade básica de análise de qualquer comportamento, como sendo uma interação deste com eventos antecedentes e eventos consequentes num determinado ambiente. A proposta de Skinner (1953/2007) foi desenvolvida na área do consumidor para explicar como eventos antecedentes e consequentes têm efeito na escolha de consumidores por intermédio do BPM (Foxall, 2016).

O BPM, desenvolvido por Foxall (2016), propõe que o comportamento do consumidor é o resultado de uma interação entre eventos antecedentes e consequentes ao comportamento (Figura 1). Os eventos antecedentes que modelam o comportamento de consumo estão integrados pelo cenário de consumo e pela história de aprendizagem.

O cenário de consumo inclui: as regulações (p. ex.: o consumo de calmantes controlados nas farmácias requer apresentação de receita médica), os estímulos sinalizadores de comportamentos de consumo que carregam consigo benefícios (p. ex.: o consumo 
de produtos orgânicos melhorará a saúde) ou consequências indesejadas (p. ex.: o consumo de cigarros necrosará o seu pulmão),; os estímulos sociais, que sinalizam comportamentos que serão reforçados socialmente na comunidade de referência (p. ex.: "dê preferência a produtos fabricados no país"); e os estímulos temporais, que sinalizam o comportamento de consumo com consequência dos diferentes tempos de espera para a sua obtenção (p. ex.: "abra uma poupança agora para ter, no futuro, uma aposentadoria tranquila").

Complementando o cenário de consumo, a história de aprendizagem do indivíduo inclui as experiências prévias de reforço e/ ou punições (experiências aversivas) no passado, assim como a maior ou menor sensibilidade aos estímulos ambientais do passado. A interseção do histórico de aprendizagem do consumidor (experiência) com o cenário de consumo define a situação do consumidor e age como precursor imediato do seu comportamento (Foxall, 2015). Ambos os elementos, cenário e história de aprendizagem, convergem como os eventos antecedentes ao comportamento do consumidor.

Por outro lado, os eventos consequentes ao comportamento do consumidor, isto é, as consequências aos quais é dirigido o comportamento (Oliveira-Castro \& Foxall, 2017) podem ser: (1) reforços ou benefícios informativos e utilitários, isto é, provenientes do entorno e da aceitação social (p. ex.: um automóvel sofisticado e caro informa status) ou do uso direto do produto (p. ex.: feijão alimenta) ou do serviço (p. ex.: transporte que é público); e (2) punições ou consequências indesejadas informativas ou utilitárias, isto é como no caso anterior, relacionadas a uma avaliação social indesejada (p. ex.: ser rejeitado em algum lugar por trajar roupa inadequada) ou pelo uso direto do bem (p. ex.: índices nutritivos de algum alimento, altas taxas de gordura). Em resumo, a contingência que moldará e manterá o comportamento do consumidor estará constituída, de um lado, pelo escopo da configuração do comportamento do consumidor (história e cenário de consumo); e, do outro, pelo padrão de reforço proporcionado pelos produtos e serviços disponíveis (Foxall, 2015).

A aplicação do BPM propõe explicar e predizer o comportamento de consumo conhecendo o histórico de consumo, intervindo no cenário comportamental (maior ou menor abertura, estímulos discriminativos e operações motivadoras) e nas consequências para a escolha do consumidor (Foxall, 2015). As intervenções nos eventos antecedentes e ou consequentes serão realizadas pelas empresas por meio de suas práticas de marketing na relação bilateral entre consumidores e a empresa de marketing (Vella, 2015) como também por órgãos governamentais que podem restringir ou ampliar o cenário de consumo por meio de estabelecimento de regulamentações, atividades de fomento ou desincentivo ao consumo.

No estudo de Foxall, Oliveira-Castro, James, Yani-de-Soriano e Sigurdsson (2006), o modelo foi aplicado para interpretar comportamentos do consumo que deterioram o meio ambiente (p. ex.: uso de transporte privado, consumo de energia doméstica, descarte de resíduos e consumo de água). Utilizando o BPM, foi possível identificar algumas implicações para as atividades de marketing da empresa, de forma a modificar cada uma dessas classes de comportamentos. Como exemplo do estudo, os autores propuseram, para o comportamento de consumo excessivo de água, a abordagem do composto de marketing "produto", desenvolvendo uma estratégia de marketing de aumento de preço por consumo de água incluindo feedback mensal de diminuição do valor pago.

Foxall (2015) apresenta algumas pesquisas bem sucedidas no âmbito de preocupações ambientais, em que a aplicação do BPM tem propiciado intervenções realizadas por meio das atividades de marketing da empresa, dentro da relação bilateral empresa consumidor. Uma das intervenções apresentadas foi em relação ao com- portamento de uso de transporte privado. As pesquisas apontaram que o elemento crucial do mix de marketing era o produto com alto reforço utilitário e alto reforço informativo. Dessa forma, o foco das medidas de marketing foi a provisão de benefícios entregues pelo transporte privado; isto é, conforto, velocidade e confiabilidade, combinados com melhoria de status.

Para o presente artigo, a projeção de cenários futuros que possam propor a adoção de medidas em um sentido ou em outro apresenta maior complexidade. Isso ocorre, principalmente, pela grande magnitude das mudanças no cenário, com níveis de abertura e de fechamento agindo de forma instável; sem conhecimento, ainda, das consequências a serem obtidas como produto do comportamento de consumo atual.

Os níveis de incerteza do cenário pós-pandemia dificultam o planejamento das intervenções a serem implementadas. Visando a reduzir essa dificuldade, pode-se recorrer à utilização do BPM que propõe uma explicação do tipo "se, então". Ou seja, se X acontece, então Y é o elemento que está controlando-o. Assim, para cada cenário, se forem observados os comportamentos $\mathrm{X}$, então os elementos que controlam o comportamento X deverão ser Y. Assim, a proposta deste artigo - além de propor explicar as causas de determinados comportamentos - é, também, estratégica, ao fornecer uma ferramenta para projetar possíveis cenários e para intervir na construção daqueles considerados desejáveis. A ferramenta também permite apoiar a tomada de decisões organizacionais, principalmente no que tange às atividades de marketing da empresa no contexto da relação bilateral entre consumidor e práticas de marketing da organização (Vella \& Foxall, 2013).

Dessa forma, o exercício proposto aqui, que considera as incertezas geradas pelo advento da COVID-19, propõe-se a contribuir para uma análise preditiva própria do BPM, com a abordagem prospectiva característica das ferramentas de cenários e suas narrativas para construir as bases para uma análise comportamental do consumo pós-COVID-19. Essa interface entre ambas as metodologias (BPM e Cenários) implica que, para cada cenário pós COVID-19 prospectado pela metodologia de cenários, pode ser realizada uma análise funcional do comportamento do consumo como interação entre: a) eventos antecedentes ao comportamento, proporcionado pela configuração do comportamento do consumidor; e b) eventos consequentes ao mesmo. Com isso, espera-se indicar que alguns estímulos no ambiente pós-Pandemia poderão ter maior efeito do que antes dela, assim como o valor subjetivo do reforço e das punições atribuídos pelos consumidores ao comportamento de consumo poderá mudar em função do contexto ambiental e da experiência adquirida na Pandemia.

Para as organizações, a implementação de exercícios e planejamentos dessa natureza poderão promover, na relação bilateral com o consumidor, uma adequação do comportamento ou práticas de marketing como uma resposta à demanda do consumidor pós-Pandemia. Isso implica na gestão das atividades que fazem parte do escopo do comportamento do consumidor, de forma que a oferta da empresa se torne mais atraente dentro das opções que o consumidor vai avaliar no momento da escolha. Dessa forma, obterá, por parte dele, o reforço (compra de produtos e serviços) e, por sua vez, fornecendo respostas adequadas ao comportamento do consumidor; sejam eles reforços utilitários, informativos ou ambos (Vella \& Foxall, 2013).

\section{Construindo Cenários Pós-Crise da COVID-19}

A ferramenta de construção de cenários, ao utilizar a metodologia prospectiva, se propõe a lidar com a incerteza e a desenhar futuros alternativos. A gênese da metodologia, hoje consolidada, deu-se na década de 1970, na qual sucessivos choques nos preços 


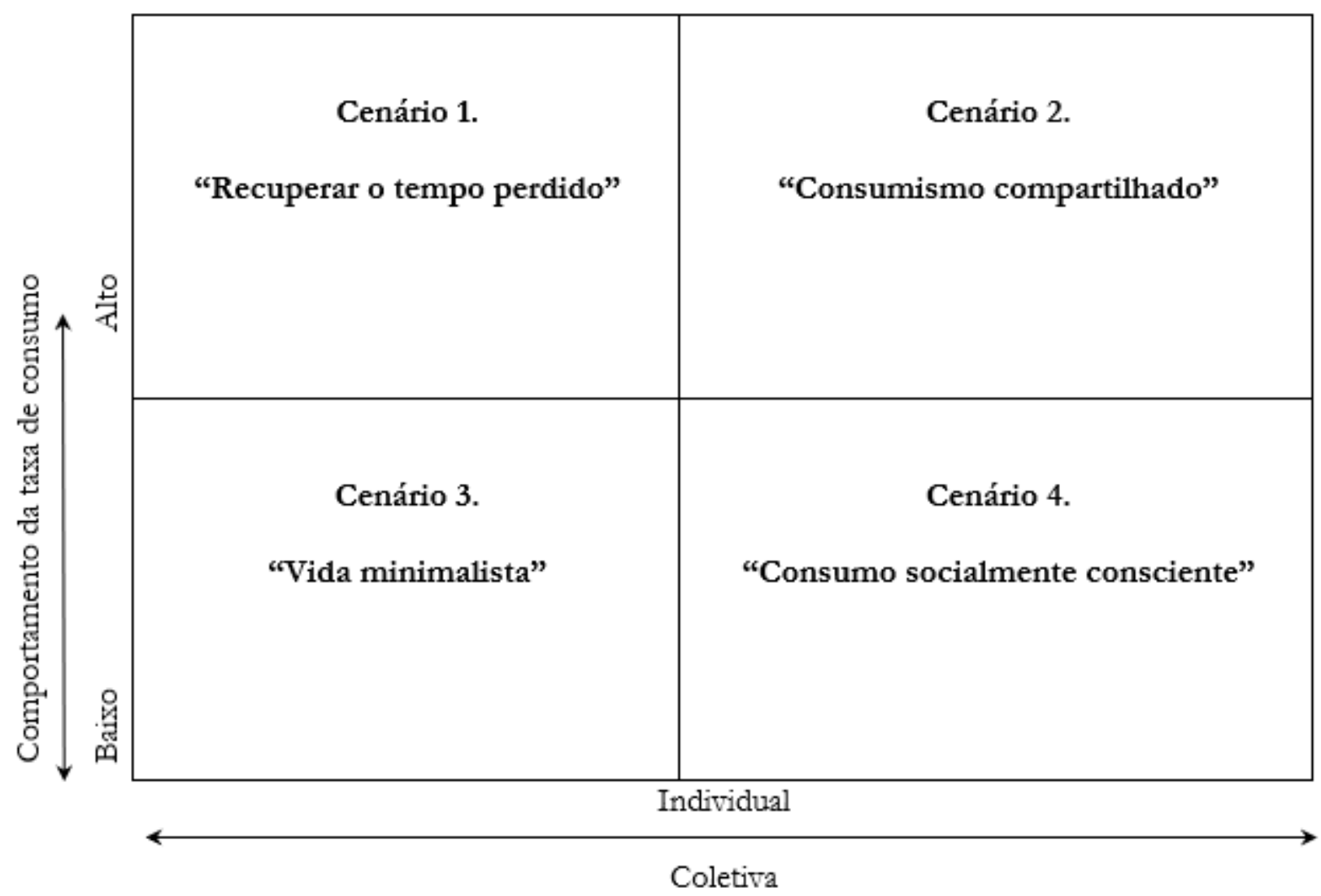

Orientação de preferência na obtenção de benefícios

Figura 2. Cenários prospectivos pós-crise da COVID-19.

do petróleo geraram incertezas críticas quanto ao futuro do combustível que foi o motor das economias em grande parte do século XX. O desenvolvimento da metodologia encontrou nas últimas décadas referências importantes em autores e pioneiros como Arie De Geus (1988), Peter Schwartz (1991, 1998) e Michel Godet (1991); e no Brasil, por autores como Claudio Porto e colaboradores (1991), Elaine Marcial e Raul Grumbach (2002).

Para responder à pergunta sobre qual será o comportamento do consumidor no futuro pós-crise da COVID-19, tenha ela uma ou mais ondas, como ocorreu com a Gripe Espanhola, ou em um convívio estendido como com a AIDS, falaremos, de qualquer forma, de um comportamento que se verá materializado e consolidado em um horizonte de três ou mais anos. Para os cenários tratados aqui, realizou-se o cruzamento de duas incertezas definidas a partir das mudanças no consumo em geral (aumento de alguns produtos e diminuição de outros) ou mudanças em relação à preferência por consumo com maior preservação ambiental. Essas variáveis permitem projetar duas linhas em que, dentro de um continuum, apresentam extremos de comportamentos em direções opostas e consideradas para o presente artigo. As de maior criticidade, quanto ao cenário do próprio consumidor, resultante dos efeitos da crise da COVID-19, são: (I) comportamento de consumo orientado à obtenção de benefícios individuais de quem consome ou, no outro extremo, preferência pelo consumo de bens e serviços com reforços coletivos, compartilhados e (II) comportamento de consumo em alta quantidade ou, no extremo oposto, comportamento orientado a um consumo em baixa quantidade ${ }^{3}$.

Justapondo estes eixos num gráfico (Figura 2), teríamos quatro cenários com os respectivos títulos que sintetizam as características e a narrativa que leva a cada um deles (Lima \& Curado 2017; Maier et al. 2016; Ramirez \& Wilkinson 2016). A narrativa dos cenários considerou que, nos próximos cinco anos, uma das alternativas possíveis quanto à evolução da pandemia se concretizará. Como exemplos dessas alternativas, citam-se: a descoberta de uma vacina (Weintraub, 2020), controle ou erradicação do vírus $^{4}$, uso de anticorpos (Sanches, 2020), alcance de massa crítica de imunização global (Aguilera, 2020) ou outro meio. O que levará à transformação da enfermidade em uma patologia respiratória de convívio regular ou sob controle vigiado, uma vez que as estimativas de probabilidade cumulativa de um dos eventos ou uma combinação deles ocorrerem nos próximos cinco anos é bastante elevada.

A partir dos possíveis cenários, o BPM propõe, para cada cenário, uma interação específica e diferente entre os eventos antecedentes e os eventos consequentes do comportamento do consumidor conforme descrito a seguir.

\section{Cenário 1: Recuperar o Tempo Perdido}

A - Narrativa. Em um certo dia do segundo semestre de 2024 o anúncio da vitória na guerra contra a COVID-19 levou a uma intensa festa patrocinada por campanhas publicitárias massivas chamando a população para as ruas, eventos de massa, shows, shopping centers, estádios de futebol. Os consumidores sentiram que este era o seu momento, que mereciam ser recompensados intensamente, pois haviam entendido que ninguém vai viver para sempre. Pequenas indulgências, grandes indulgências, viagens que sempre quiseram fazer e foram postergadas. O "momento é agora" e "eu mereço" foram os sentimentos dominantes refletidos nas comunicações publicitárias.

As lojas, shoppings, empresas aéreas e de turismo aproveitaram para enfatizar produtos com preços mais rentáveis e seus artigos

3 Considerando que o objetivo do texto não é a metodologia de construção de cenários, este texto traz o resultado do exercício de oito passos realizado descritos no livro de Peter Schwartz (1998)

4 Como no caso do Ebola e outras epidemias virais anteriores na história, ou como logrado pela China e Coréia do Sul na pandemia da COVID-19. 
com maior margem de retorno. O reajuste crescente de preços gerou um processo inflacionário e os preços relativos terminaram por confundir o consumidor, que pareceu não se importar. A disponibilidade de crédito, tímida nos primeiros meses do retorno ao consumo, apresentou-se como um instrumento fundamental para sustentar o crescimento das vendas. Os produtos importados de luxo voltaram às prateleiras e encheram os olhos dos consumidores com suas promessas de realização e satisfação infinitas.

No outro extremo, a massa de desempregados e subempregados, gerados pela crise, beneficiaram-se marginalmente do processo, seja pelo retorno do processo de emprego, seja pela abertura de possibilidade de crédito. Mas a oferta dos produtos essenciais terminou entrando na espiral da inflação, neutralizando parte dos ganhos obtidos com o aumento do emprego e do acesso ao crédito. $\mathrm{O}$ mercado se segmentou em dois grandes grupos, aqueles que conseguiram manter sua renda durante a crise e aqueles que foram excluídos do mercado de trabalho. Enquanto aqueles que conseguiram manter sua renda foram consumir intensamente, recompensando-se pelas privações passadas, o outro extremo simplesmente tentou reiniciar sua vida, gerando problemas de demanda para os grandes produtos de massa. O comércio ambulante transformou as ruas em grandes feiras a céu aberto. Os meios de promoção e publicidade enfocaram intensamente o público com maior renda, gerando uma disputa intensiva por este consumidor ávido. Nos locais comerciais, os problemas de segurança e a massa de pedintes tornaram a maioria "desinteressante", colocando os produtos e serviços de segurança novamente em evidência para as classes com melhor nível de renda. Clubes de consumo, compra por internet e uma reconfiguração das cidades começaram a ser visíveis com o surgimento e avanço dos bairros em processo de deterioração socioeconômica e de insegurança.

B - Análise Comportamental. O aumento exacerbado das taxas de consumo descrito neste cenário, desde o BPM, é explicado pelos eventos antecedentes e consequentes ao comportamento do consumidor, os quais se analisam a seguir para este primeiro cenário. Entre os antecedentes, o cenário apresenta níveis de abertura similares aos anteriores à Pandemia, quando não existiam maiores restrições por parte de órgãos governamentais em relação ao funcionamento de centros comerciais e lojas físicas em geral. As empresas procuram recuperar as perdas sofridas na Pandemia, desenvolvendo uma série de atividades de marketing de forma a agir (estímulos e operações motivadoras) como eventos antecedentes ao consumo.

Assim também as compras on-line, comportamento modelado na Pandemia, permanecem somando-se aos níveis de consumo em ambiente físico, produzindo efeito reforçador no consumidor, manifestados pela alta quantidade e intensidade do consumo como resposta a uma maior sensibilidade aos estímulos que estiveram ausentes no ambiente anterior durante o combate à COVID-19. Em relação às regulamentações, a mudança da normativa restritiva da depressão econômica passa para uma regulamentação mais permissiva, adicionando medidas de fomento à criação de novas empresas, pela diminuição de juros para consumo, a abertura do ambiente de consumo, com diversos canais de consumo e fontes de recursos para o consumo. Os estímulos sociais e temporais promovem a escolha por benefícios imediatos, dirigidos ao próprio consumidor; existe uma ênfase na aceitação e reconhecimento social, pertencer a grupos fortalecendo consumo de bens e serviços que incorporem reputação por meio de grandes marcas reconhecidas no mercado. Quanto aos eventos consequentes: No continuum de preferência de consumo de produtos com benefícios (sejam informativos ou utilitários), com aproveitamento ou distribuição individual ou maior tendência ao coletivo ou compar- tilhado, o consumidor preferiria nesse cenário produtos e serviços com benefícios próprios ou para pessoas com pouca distância social dele (Locey, Safin, \& Rachlin, 2013) que tenham alto nível informativo de status ou reputação. Escolhe marcas com tradição de status, assim como não existiria uma preocupação pela escolha de produtos e serviços com benefícios de longo prazo (caso não entreguem prestígio), nem preferências por reforços a serem compartilhados com pessoas distantes socialmente. Um exemplo deste tipo de escolha são as viagens a lugares cujos benefícios de consumo são usufruídos pela pessoa que compra e em que a empresa, pelo seu tamanho e diversidade de clientes, não depende da preferência de um cliente em particular, como acontece geralmente com os negócios pequenos. Exemplo disto podem ser viagens a lugares em que os negócios pertencem às grandes empresas (p. ex.: Disney World). Neste cenário, instrumentos de marketing como segmentação e propaganda se tornam instrumentos importantes para poder atingir especificamente grupos de maior renda, bem como para traduzir elementos aspiracionais dos produtos e serviços. Produtos comunicados como "experiências de vida", "experiência única" e outros atributos com alta reputação são usados amplamente. No composto de "praça" a logística eficiente e segura torna-se o elemento mais relevante.

\section{Cenário 2: Consumismo Compartilhado}

A - Narrativa. O anúncio de que a humanidade havia vencido a COVID-19 fez com que as ruas explodissem em eventos sucessivos e crescentes de comemorações em massa. Como uma final de copa do mundo, as pessoas explodiram em comemorações carnavalescas. Lotaram as ruas, se abraçavam e beijavam em blocos, compartilhando cervejas, garrafas de água e comida. Era uma festa de fartura compartilhada nas ruas, brigas eram paradas e não eram toleradas na multidão. Foram desenvolvidas campanhas para apoio de afetados pela COVID-19 convidando a doar alimentos, roupas, eletrônicos, afinal todos tinham que estar conectados. Os consumidores procuraram pequenos produtores para comprar deles, assim como produtos e bens para serem compartilhados.

A divisão entre os que mantinham o emprego e os que não tinham emprego era visível, mesmo assim as campanhas empresariais, de grupos de amigos, igrejas e associações não paravam de arrecadar dinheiro para comprar comida e ajudar as pessoas que estavam em situações de maior dificuldade. O festejo e as campanhas de ajuda material às pessoas em dificuldade dominavam as mídias. Lojas, shoppings e sites de internet tinham pelo menos uma campanha de apoio. Pessoas juntas, diversas, coloridas e sorrindo era o fundo de toda campanha promocional.

As empresas de turismo e os pacotes para viagens em grupos aumentaram a demanda. Estádios de futebol lotados, bares e restaurantes também. As pessoas queriam estar juntas e compartilhar os benefícios da vida social. Com as ruas cheias, dia e noite, a questão de segurança passou a segundo plano. As pessoas se apropriavam de suas cidades.

Cooperativas de produção e de crédito continuam seu passo de crescimento que experimentavam antes da crise da COVID-19. Os sites de crowdfunding e fintechs $s^{5}$ se tornam negócios de rápido crescimento e, junto com as cooperativas de crédito, começaram a se materializar como um dos eixos principais de canalização do crédito.

Os meios de promoção e publicidade se massificam em campanhas horizontais, destacam em seus anúncios "pessoas felizes vivendo intensamente", cervejas, restaurantes, shows de música e esportivos, viagens para parques de entretenimento dominam as telas de televisores, celulares e outdoors. As novas unidades de

5 Crowdfunding, literalmente seria "financiamento pela multidão", é um tipo de financiamento para doações, investimentos ou crédito, no qual as pessoas aplicam pequenas quantias de dinheiro, geralmente via internet. Fintech é uma empresa que se propõe a oferecer serviços financeiros por meio da internet e instrumentos digitais. 
imóveis colocadas à venda enfatizam em suas publicidades as áreas comuns, piscinas, churrasqueiras, salões de festas, quadras esportivas.

B - Análise Comportamental. No cenário de "consumismo compartilhado", os eventos antecedentes do comportamento (p. ex.: estímulos e operações motivadoras) aparecem na relação bilateral entre a empresa e o consumidor (Vella, 2015) por meio de estratégias comunicacionais e de marketing. Essas estratégias promovem comportamentos de consumo mais orientados ao coletivo, sinalizando as consequências indesejadas obtidas durante a Pandemia, produto de comportamentos orientados a benefícios individuais ou sem atentar à preservação coletiva. Observa-se um aumento nos índices gerais de consumo, produto da sensibilidade às estratégias comunicacionais para recuperação dos índices de consumo e da economia. O histórico de reforços e punições recentes do comportamento de consumo apresenta um efeito significativo nas escolhas no novo cenário, mostrando aumento nas preferências do consumidor pela escolha de reforços orientados ao coletivo em detrimento do individual. As consequências indesejadas que foram vivenciadas na propagação da Pandemia, produto de escolhas de benefícios somente em nível individual (não uso de máscara, não cumprimento de isolamento), agem como estímulos sinalizadores de punições do comportamento de consumo no novo cenário. Do ponto de vista do controle que exercem as consequências sobre o comportamento, o consumo de bens e serviços que trazem benefícios compartilhados, coletivos ou para pessoas distantes socialmente do consumidor são preferidos na escolha do consumidor (Locey et al., 2013). Os reforços coletivos podem se referir a benefícios para o ambiente, para o produtor ( $\mathrm{p}$. ex.: "apoie uma microempresa"), para o entorno comunitário ou para pessoas distantes socialmente que, de forma geral, promovem o meio ambiente, o bem estar coletivo e a promoção de benefícios compartilhados. A mídia os órgãos governamentais e as atividades de marketing da empresa, em geral, promovem e reforçam socialmente o tipo de escolha descrito como sendo comportamentos desejáveis. Para este cenário, os instrumentos de marketing com apelo ao consumo coletivo se tornam eficientes. A propaganda e segmentação direcionada às "tribos", comunidades e "paróquias" são instrumentos efetivos. No composto de "praça", a localização e logística privilegiam a proximidade, a escolha pelo local. As promoções são diversas e numerosas tanto no comércio eletrônico quanto no comércio tradicional. Uma grande quantidade de empresas adicionou comércio eletrônico a seus canais de venda e a abertura de cenário fomenta a proliferação de medidas de promoção para a atração de clientes que respondem com aumento nas taxas de consumo.

\section{Cenário 3: Vida Minimalista}

A - Narrativa. Era uma tarde de domingo de primavera, em 2025, e das casas se ouvia o anúncio de que a COVID-19 passava à história da humanidade, ao que se sucederam dois meses de vacinação massiva de casa em casa e em drive thru indicados pelas prefeituras. As pessoas saíam de casa, tranquilas, algumas ainda de máscara, caminhando umas distantes das outras. O movimento nos supermercados aumentou, mas os carrinhos de compras se mantiveram mais austeros e com produtos essenciais (p. ex.: feijão, arroz, frutas).

O comércio de rua e shopping centers reabriram, mas da mesma forma que aconteceu com outras lojas que reabriram, uma atrás da outra, começaram a fechar as portas, já que o consumidor "não voltou". Nas revendas de automóveis os modelos mais luxuosos "encalhavam", enquanto as vendas de automóveis mais econômicos e menores aumentavam moderadamente. A demanda por serviços de conserto de roupas, carros, eletrodomésticos aumentou. Os adolescentes e jovens começaram a se embalar por músicas hindu e camisetas estampadas com Gandhi e estilo hippie, lembrando os anos 1970, substituíam as marcas famosas. As pessoas nas ruas estão calmas, passeiam sem pressa e com vestimentas confortáveis que sirvam às suas necessidades. Homens e mulheres mais ao natural.

A decoração minimalista estilo japonesa remodelava as residências; tutoriais e vídeos "faça você mesmo" no Youtube se multiplicaram para soluções decorativas das casas, roupas e utensílios. Cadeias de lojas de tecidos, papelarias, materiais de construção e de madeiras criam unidades de proximidade nos bairros, oferecendo cursos gratuitos. As famílias e negócios reduzem seus níveis de endividamento e o serviço financeiro retornava gradativamente ao que era no século XX, tornando-se acessórios, as agências bancárias, menores e mais simples, retornavam às quadras e os gerentes das agências se tornam assessores financeiros de seus clientes e dos negócios de bairro.

Pessoas passaram a entender que não precisavam viver nos grandes centros urbanos, começam a preferir cidades menores onde o custo de vida é mais barato. Menos diferença econômica tornava as pessoas com mais bens muito visíveis e socialmente desincentivadas, além de virarem alvos fáceis para a criminalidade literalmente marginal nas cidades, pois não havia muito o que roubar.

B - Análise Comportamental. Neste cenário, é observada a baixa taxa de consumo e preferência na escolha por consumo de bens e serviços com reforços ou benefícios individuais. Nos antecedentes ao comportamento, os estímulos físicos e sociais sinalizam os resultados indesejados obtidos no passado recente pelo excesso de consumo, assim como destacam a absorção individual dos benefícios ou para pessoas com pouca distância social (Locey et al., 2013) por ter diminuído as taxas de consumo. Como consequência, ocorre a diminuição nos montantes a pagar nas faturas de cartão de crédito, menor endividamento, entre outros aspectos reforçadores da diminuição no consumo. No histórico de consumo, como produto das restrições do ambiente ao consumo, o consumidor pode ter entrado em contato com a consequência de não consumir, o que faz parte do seu aprendizado. Se essas consequências do baixo consumo durante a pandemia foram reforçadoras ou trouxeram benefícios percebidos, muito provavelmente serão antecedentes para os novos comportamentos narrados no cenário. Neste caso, o consumidor diminui a taxa de consumo passando a consumir somente o que é estritamente necessário às suas necessidades individuais. Analisando as consequências, é possível que o consumidor, após a pandemia, receba um reforço advindo do consumo de menor magnitude, ou seja, o valor que atribuía a um reforço, por exemplo social, já não possui a mesma magnitude ou importância. O consumidor prefere bens e serviços cujos benefícios sejam para ele, não importando o tipo de empresa ou marca da qual compra, assim como desconsidera benefícios compartilhados. A preferência é pelo menor, mais simples e mais econômico possível. Em relação aos benefícios ou reforços mais utilitários ou informativos (Foxall, 2015) o consumidor consome o necessário, preferindo os bens e serviços com valor utilitário em contraposição aos benefícios informativos que, neste cenário, têm pouco efeito no comportamento dele. Da mesma forma, as consequências indesejadas com maior componente utilitário são as que têm efeito no consumidor (p. ex.: baixo valor nutricional, alto custo de compra) assim como as punições de caráter mais informativo não têm maior influência na decisão de consumo.

Para este cenário, os instrumentos de marketing desenvolvidos pelas empresas na relação bilateral empresa consumidor (Vella, 2015) focam em destacar os benefícios utilitários dos produtos e 
como eles atendem necessidades básicas dos consumidores, adicionando serviços acessórios que aumentem o poder do consumidor e integração com o processo produtivo (p. ex.: acesso a plataformas e tutoriais para reparação do produto pelo próprio consumidor); produtos com atributos de economia e durabilidade conquistam a preferência dos consumidores. A propaganda apresenta pouca efetividade, outras medidas de promoção de baixo custo e mais personalizadas se demonstram mais adequadas e com possibilidade de ser mais bem recebidas pelos consumidores. No composto de "praça", simplicidade na lógica "small is beautiful" é a plataforma mais adequada.

\section{Cenário 4: Consumidor Responsável}

A - Narrativa. Os vizinhos cumprimentavam-se sistematicamente. As portas abertas e as conversas nos corredores se intensificaram em edifícios residenciais, escolas, universidades e escritórios. Era evidente a satisfação de cada bom dia ou boa tarde trocado entre as pessoas. Esse foi a mudança mais evidente depois que o anúncio de que a comunidade global havia recolocado definitivamente a COVID-19 de volta em seu lugar na natureza. Era dia de Nossa Senhora de Aparecida de 2024. Depois de um processo de fechamento em massa em lojas de rua e shoppings, novos negócios começam a surgir, mas em menor quantidade. Negócios de proximidade com seus clientes, lojas de bairro e minimercados substituíram as grandes lojas de departamento e os hipermercados. As políticas de distanciamento deixaram marcas e as aglomerações passaram a causar mal-estar entre as pessoas.

As grandes cidades começam a perder população, pois as pessoas entenderam que precisam consumir menos para um mundo sustentável e que é mais importante viver próximo de pessoas com as quais elas se identificaram mais e de onde a comida era produzida. Uma cultura de aldeias e vilas começava a emergir, pessoas vivendo próximas umas das outras em torno de outros valores para além do consumo. A degradação de bairros inteiros, abandonados, nas cidades maiores tornou-se foco de ação de associações comunitárias e mutirões para adaptar o uso dos espaços urbanos orientados à produção próxima de produtos e serviços.

Alguns prédios, casas e galpões terminaram sendo demolidos, abrindo espaço para praças, bosques e hortas urbanas. Os preços, depois de um processo deflacionário, se estabeleceram em níveis razoavelmente estáveis, os produtos essenciais ganharam valor relativamente aos outros produtos; produtos de luxo continuam circulando, mas restrito a nichos culturais. Produtos com rótulos evidenciando suas qualidades ambientais e sociais aumentaram, mas mesmos esses são vistos com certa desconfiança por estarem orientados ao consumo de massa. A origem e proximidade dos produtores passava a ser mais relevante.

O dinheiro físico voltou a circular mais intensamente, mas o surgimento de moedas tecnológicas-sociais criou uma série de nichos territoriais, com tecnologias e desenvolvimentos localizados. As tentativas de consolidar essas plataformas para que ganhassem escala gerou desconfiança entre os consumidores, fazendo com que a maioria das iniciativas fracassassem. Produtos oriundos de cooperativas e associações de produtores ganhou força e se tornaram importantes empregadores na economia real. No setor financeiro, um processo similar fortaleceu a atuação das cooperativas de crédito.

B - Análise Comportamental. Antecedentes. No histórico de consumo deste cenário, o consumidor teve contato com consequências reforçadoras advindas do baixo nível de consumo no cenário de consumo mais fechado durante a pandemia, estando menos sensível aos estímulos que promovem maior consumo, como acontece em cenários de consumo aberto em que várias respostas de consumo são possíveis para o consumidor (Dias \& Oliveira-Castro, 2003). Nas consequências, o pouco que consome reforça a preferência por produtos e serviços cujo consumo traz benefícios coletivos ou compartilhados com pessoas distantes socialmente (Locey et al., 2013). O consumidor escolhe comprar pouco, do produtor pequeno ou produtos sem danos ambientais. Prefere produtos com reforços informativos associados ao compartilhamento, ao coletivo, à preservação ambiental e comunitária Estímulos relativos a uma seleção de comportamentos com foco no coletivo e cultural ou com significância para a preservação da espécie (Baum, 2015) poderão ter maior sucesso comparativamente àqueles com ganhos somente individuais, pois a contingência parece estar mostrando que o bem-estar individual de forma sustentável passa necessariamente pelo bem-estar coletivo. Em relação às punições ou consequências indesejadas, tanto o informativo (p. ex.: ter uma reputação de individualista) quanto o utilitário (p. ex.: alto preço) tem efeito na decisão de compra (Foxall, 2015).

Neste cenário, instrumentos de marketing do produto ou serviço na relação bilateral empresa consumidor (Vella, 2015) devem enfatizar seus vínculos com o ambiente e a sociedade de forma a adicionar reforçadores para o consumidor, preocupados com as variáveis coletivas na tomada de decisão. A embalagem tende a desaparecer, assumir o caráter de reuso ou ser retornável e reutilizável. A propaganda apresenta pouca efetividade, mas deve vincular-se com pessoas e o meio ambiente. No composto de "praça", eficiência energética é a palavra de ordem.

\section{Implicações para Organizações}

Dependendo de quais sejam os objetivos dos países e das instituições, podem ser promovidas diferentes ações e políticas tanto em nível público como privado. Empresas que procurem recuperar as perdas monetárias resultantes da pandemia provavelmente focarão em medidas de marketing que apresentem estímulos e cenários de escolha de forma a promover o aumento do consumo e ganhar como empresa os benefícios desejados. Entretanto, o advento da pandemia evidenciou os efeitos a longo prazo de certas estratégias e ações orientadas à obtenção de benefícios puramente individuais, ou mesmo privilegiando somente o indivíduo.

Empresas podem sinalizar uma série de reforçadores para o consumo de bens, porém o consumidor terá na sua história de aprendizagem a experiência vivida durante a pandemia da COVID-19. A punição advinda do comportamento de isolamento individual será um antecedente para novas escolhas de consumo, o que implica que os estímulos sinalizadores de benefícios emitidos tradicionalmente pelas empresas terão seu efeito considerando as contingências vivenciadas. Antigas estratégias de marketing podem não apresentar mais a mesma efetividade sobre a decisão de compra demonstrada anteriormente e, ainda mais, podem gerar reputações não acordes a novos benefícios preferidos pelos consumidores (Fagerstrom et al., 2015).

Organizações públicas e de desenvolvimento poderão vivenciar uma janela de oportunidades para promover comportamentos com maior orientação ao coletivo, promovendo comportamentos orientados à preservação ambiental e sustentável, desenvolvendo atividades comunicacionais e de marketing. Atividades estas que sinalizam as consequências reforçadoras de certos comportamentos de preservação ambiental (Foxall et al., 2006), sanitária ou socioeconômica, intervindo não somente no nível de estímulos, quanto reforçando ou punindo certos comportamentos. $\mathrm{Na}$ medida em que o consumidor atribui valor ao reforço advindo de comportamentos de preservação coletiva e, ainda, considerando que esses benefícios podem chegar com uma certa demora ou atraso no tempo, se facilita a construção de cenários de maior sustentabili- 
dade social e econômica.

A assertividade e a aproximação a cada cenário se darão com o desenvolvimento dos acontecimentos, cabendo a cada organização criar indicadores próprios para identificar o quanto se aproxima, o quão profundamente a realidade está mergulhando em cada cenário e, com ele, desembarcar com agilidade as medidas e planos desenvolvidos para cada um desses territórios operacionais pós-Pandemia. E, com eles, as medidas nos antecedentes e nos consequentes que poderão ser aplicadas, quais estímulos serão mais destacados ou que benefícios serão vinculados aos tipos de consumo, intervindo nos elementos que, em última instância, interagem com os cenários em que se dão.

\section{Referências}

Aguilera, J. (2020). No, You Should Not Have or Participate in a Coronavirus Party. Here's What to Know About Herd Immunity. Recuperado de https://bit. ly $/ 2 \mathrm{FKseh} 8$

Balinska, M., \& Rizzo, C. (2009). Behavioural responses to influenza pandemics: what do we know? PLoS currents, 1, RRN1037, 1-15. https://doi. org/10.1371/currents.rrn1037

Barata, G. (2006). A primeira década da Aids no Brasil: o Fantástico apresenta a doença ao público (Dissertação de mestrado). Recuperado de https://bit.ly/2Td5Vnu

Baum, W. M. (2015) Driven by Consequences: The Multiscale Molar View of Choice. Managerial and Decision Economics, 37, 239- 248. https://doi. org/10.1002/mde. 2713

Becker, M., \& Joseph, J. (1988). AIDS and Behavioral Change to Reduce Risk: A Review. American Journal of Public Health (AJPH), 78(4), 394-410. https://doi. org/10.2105/ajph.78.4.394

Dias, M. B., \& Oliveira-Castro, Jorge M. (2006). Comportamento de procura por produtos: efeitos da quantidade de marcas. Revista Psicologia Organizações e Trabalho, 6(1), 195-232. Recuperado de https://bit.ly/324hthC

Fagerstrom, A., Stratton, J. P., \& Foxall, G. R. (2015). The Impact of Corporate Social Responsibility Activities on the Consumer Purchasing Situation. Journal of Organizational Behavior Management, 35(3-4), 184-205. https://doi.or $\mathrm{g} / 10.1080 / 01608061.2015 .1093053$

Foxall, G. R. (2015). Consumer Behavior Analysis and the Marketing Firm: Bilateral Contingency in the Context of Environmental Concern. Journal of Organizational Behavior Management, 35(1-2), 44-69. https://doi.org/10.1080/ $\underline{01608061.2015 .1031426}$

Foxall, G. R. (2016). Consumers in Context: The BPM Research Program. Londres: Routledge.

Foxall, G. R. (2017). Behavioral Economics in Consumer Behavior Analysis. Behavior Analyst, 40, 309-313. https://doi.org/10.1007/s40614-017-0127-4

Foxall, G. R., Oliveira-Castro, J. M., James, V. K., Yani-de-Soriano, M. M., \& Sigurdsson, V. (2006). Consumer Behavior Analysis and Social Marketing: The Case of Environmental Conservation. Behavior and Social Issues, 15 101-125. https://doi.org/10.5210/bsi.v15i1.338

Geus, A. (1988). Planning as learning. Harvard Business Review, 1-11. Recuperado de https://bit.ly/34fNqFi

Godet, M. (1991) Problemas e métodos de prospectiva: caja de herramientas. Zarautz: Prospektiker Erakundea, D.L.

Lewis, D., \& Bridger, D. (2000). The Soul of the New Consumer: Authenticity - what We Buy and why in the New Economy. Londres: Nicholas Brealey Publishing.

Lima, R., \& Curado, M. (2017). O Futuro do Estado no Brasil e seus Impactos na Sociedade: questões para o desenvolvimento até 2035. Brasília: Ipea (Instituto de Pesquisa Econômica Aplicada).

Locey, M. L., Safin, V., \& Rachlin, H. (2013). Social Discounting and the Prisoner's Dilemma Game. Journal of the Experimental Analysis Behavior, 99 , 85-97. https://doi.org/10.1002/jeab.3

Maier, H., Guillaume, J., Van Delden, H., Riddell, G., Haasnoot, M., \& Kwakkel, J. (2016). An uncertain future, deep uncertainty, scenarios, robustness and adaptation: how do they fit together? Environmental Modelling \& Software, 81, 154-164. https://doi.org/10.1016/i.envsoft.2016.03.014

Marcial, E., \& Grumbach, R. (2002). Cenários Prospectivos - Como Construir um Futuro Melhor. Rio de Janeiro: FGV.

Oliveira, P. (2020). Coronavírus altera hábitos de consumo e impacta mercado. Recuperado de https://www.mundodomarketing.com.br/ultimas-noticias/38582/ coronavirus-altera-habitos-de-consumo-e-impacta-mercado.html

Oliveira-Castro, J. M., \& Foxall, G. R. (2017). Consumer Maximization of Utilitarian and Informational Reinforcement: Comparing Two Utility Measures with Reference to Social Class. Behavior Analyst, 40, 457-474. https://doi.org/10.1007/s40614-017-0122-9

Porto, C., Souza, N., \& Buarque, S. (1991). Construção de cenários e prospecção de futuros. Recife: Litteris.
Ramirez, R., \& Wilkinson, A. (2016). Strategic reframing: The Oxford scenario planning approach. Oxford: Oxford University Press.

Sanches, D. (2020). Anticorpos de thama podem ser usados para combater o novo coronavirus. Recuperado de https://bit.ly/37okjS1

Schwartz, P. (1991). The Art of the Long View: planning for the Future in an Uncertain World. Nova Iorque: Doubleday.

Schwartz, P. (1998). Scenario Planning: Managing for the future. England: Wet Sussex.

Skinner, B. F. (1953/2007). Ciência e Comportamento bumano (João Carlos Todorov e Rodolfo Azzi, trad.). São Paulo: Martins Fontes.

Vella, K. J. (2015). From consumer corporate response to. Em G. R. Foxall (Org.), The Routledge Companion to Consumer Behavior Analysis (pp. 272-295). Londres: Routledge.

Vella, K. J., \& Foxall, G. R. (2013). The Marketing Firm: Operant Interpretation of Corporate Behavior. Psychological Record, 63, 375-402. https://doi. org/10.11133/i.tpr.2013.63.2.011

Weintraub, A. (2020). It could take 5 years for 2 leading COV ID-19 vaccines to debut, AI analysis finds. Recuperado de https://bit.ly/2TbeOxR

\section{Informações sobre os autores:}

\section{Andrea Carolina Droguett Jamett}

Instituto de Psicologia, Universidade de Brasília (UNB)

Campus Universitário Darcy Ribeiro ICC Sul

70910-900, Brasília, DF, Brasil

E-mail: andreadjamett@gmail.com

\section{Luciano Teixeira Schweizer}

E-mail: lucianoschweizer@yahoo.com.br 